\title{
Mobility of Knowledge Work and Affordances of Digital Technologies
}

\author{
Sarah Beth Nelson
}

School of Information and Library Science, University of North Carolina at Chapel

\section{Mohammad Hossein Jarrahi}

School of Information and Library Science, University of North Carolina at Chapel

\section{Leslie Thomson}

School of Information and Library Science, University of North Carolina at Chapel

\begin{abstract}
The focus of this work arises from two needs within information science literature: 1) to understand more, from an empirically driven perspective, about the increasingly visible yet understudied mobile work population, and 2) to address more clearly, from a theoretical standpoint, the ways in which information and communication technologies (ICTs) mediate the work practices of these mobile workers. Drawing on the affordance perspective, this research goes beyond simplistic conceptualizations of technological effects to explore the roles of multiple ICTs in enabling mobile knowledge work. In this paper, the use of ICTs in mobilizing information practices and the ways in which ICTs generate affordances along different mobility dimensions (spatial, temporal, contextual, and social) are examined. The empirical base of this research is a field of study of 33 mobile knowledge workers (MKWs); broadly, it focuses on the ways they employ ICTs to accomplish work in dynamic and unpredictable work conditions.
\end{abstract}

\section{Keywords}

Knowledge work, mobile devices, information practices, digital technologies

\section{Introduction \& related literature}

According to recent predictions, the U.S. mobile worker population will grow at a steady rate over the next five years, increasing from 96.2 million in 2015 to 105.4 million mobile workers in 2020 (IDC, 2015). Information and communication technologies (ICTs) play no small part in the continued rise of this population (Ciolfi \& de Carvalho, 2014; Su \& Mark, 2008), affording them the opportunity to work 'anytime, anyplace' (Davis, 2002) and assisting in their connectivity across locales, far beyond the traditional, centralized office nucleus. How mobile knowledge workers (MKWs)--those who not only extend and expand 
(Middleton, 2008) the spaces, times, organizations, and projects across which they work by choice and by requirement--employ ICTs to accomplish work in dynamic and unpredictable conditions is the focus of this paper.

The mobile knowledge work context is distinct from the "small world" (Huotari \& Chatman, 2002) organizational model often discussed in the information science literature. First, many MKWs have no centralized organization of which to speak, but 'orbit' around clients and colleagues and through an extended professional network (Costas, 2013; Czarniawska, 2014). For them, an upper management has not supplied and dictated the specific use of such things as hardware, software, systems, applications, standards, and policies (Huotari \& Wilson, 2001). Rather, MKWs face a persistent reality of mobility across spaces, times, organizations, projects, and other borders; their work tools must be able to withstand this and to work independently of a centralized system or structure, since intra-company virtual access or even standard connectivity may, at any time, become unexpectedly unavailable (Su \& Mark, 2008). This requires technological capability to be sure, but also adept 'mobilization work' on the parts of MKWs themselves (Perry \& Brodie, 2006), which involves extra activities and planning for spatial mobility and temporal shifts. It is the premise of this and several of our other papers to date that the information science field has not yet fully addressed the labyrinthine nature of the mobile work context (Jarrahi \& Thomson, forthcoming; Thomson \& Jarrahi, 2014; Thomson \& Jarrahi, 2015).

Information science scholars interested in information practices have made professionals in traditional work arrangements a common population for their studies (e.g., Courtright, 2007; Julien, Pecoskie, \& Reed, 2011). Their investigations have furnished valuable insights about the patterns of acquiring, seeking, chaining, using, and retaining information materials discernible within several venerable fields, including engineering, science, healthcare, law, as well as other areas of academia (e.g., Allen, Wilson, Norman, \& Knight, 2008; Leckie, Pettigrew, \& Sylvain, 1996). As Veinot (2007) points out, these are all prototypical knowledge professions that stress the cognitive, analytical, creative, and problem-solving capabilities of those who carry them out. The need for site-specific resources or time-specific functionality is very rarely present for knowledge workers (e.g., Davis, 2002), and an ever-expanding suite of ICT features enables their mobility even more so.

A few information science scholars have pointed out a weak theorization of ICTs in information practices research, particularly professional information practices research (Allen, Karanasios, \& Slavova, 2011; Järvelin \& Ingwersen, 2004). Sawyer and Huang (2007), following Orlikowski and lacono (2001), discussed five conceptualizations of ICTs found across information science and information systems literatures. In one view, the most commonly taken approach to ICTs and the one preferred in the Journal of the Association of 
Information Science \& Technology (JASIST) publications about 40 percent more frequently than in Information Systems Research publications (Sawyer \& Huang, 2007), is where ICTs are relatively unproblematized. They are depicted as tools with various identifiable features that operate wholly in line with their design to produce certain effects and impacts. In their analysis of literature, Sawyer and Huang (2007) also found 58 percent of JASIST publications do not engage ICTs beyond the artifact level. They argue, as we do here, that developing a deeper understanding of the relationship between information, technology, and people is worthwhile.

Along the same line, the nascent research on the context of mobile work is heavily weighted to the direct effects of technologies in creating location independence, providing instant information retrieval and faster data processing, and reducing the cost associated with mobile work (e.g., Mori, Paternò, \& Santoro, 2003; Wang, Van de Kar, \& Meijer, 2005). Inadequate attention is devoted to the challenges present in the mobile work context and in the specific needs and practices of MKWs. In addition, much of this research is focused on the integration of single technologies in mobile practices (e.g., cell phones or cloud services) (e.g., Karanasios \& Allen, 2014; Perry, 2007) even though other studies of different types of work (e.g., Jarrahi \& Sawyer, 2015), and especially mobile work (e.g., Rossitto, Bogdan, \& Severinson-Eklundh, 2014), suggest that a vast majority of knowledge workers are increasingly employing a suite of devices, tools, and technologies in their daily work practices.

The affordance and sociotechnical perspectives adopted here offer one way to address these issues. Mobile knowledge work is an especially interesting context in which to consider problematizaton of the interplay between ICTs and information practices. Here we can easily see the ways in which mobility, knowledge work information practices, and digital technologies are dependent on one another. This brief setting of the scene has shown that mobile knowledge work is a worthy and necessary object of research consideration and technology must be better scrutinized as a factor in human practices. This research adds to discussions of the interplay among information practices, the multiplicity of ICTs, and the mobility of knowledge work, which are at present scant. Mobile knowledge work is a newly emergent phenomenon, idiosyncratic, and still very much in its formative stages. However, it is only increasing in visibility. Investigating the technological habits and information needs and practices of MKWs informs technological and organizational design, and illuminates trends that are driving contemporary workforce change.

Design and implementation of new information systems has to take into account the unique ways through which MKWs manage and incorporate information and knowledge in their mobile practices (Erickson, Jarrahi, Thomson, \& Sawyer, 2014; Sørensen, 2011). MKWs undertake extra tasks, and generate specific "understanding" and "literacy" to deal with their inconsistent work environment, and to create a functioning "mobile office." (Bardram \& Bossen, 2005). In doing this, they continuously develop and call into play explicit 
and implicit forms of knowledge to be able to maneuver through multiple work spaces (Erickson \& Jarrahi, 2016; Perry, 2007). As a result, organizational information and knowledge management practices must now accommodate the particularities of remote and mobile work arrangements that increasingly become the new normal in many organizational settings.

\section{Theoretical framework}

James Gibson (1977), a perceptual psychologist, suggested that when interacting with their environment, animals and people do not perceive an object independently of its uses, and dubbed this a perception of utility "affordance." Thus, people assign meanings to object based on what they are good for. Even though objects and their features may be the same across users, affordance perceptions are likely to vary. That is, affordances are experienced in unique ways, depending on how a given social actor interprets objects in light of his or her particular situation and context. In his formulation, Gibson makes an interesting distinction between the materiality of an artifact and the affordance of an artifact. Whereas material properties refer to features such as the distinctive colors, textures, or shapes of objects that are encountered by all users in the same way, the affordances of objects may be multiple. Use of the same technology by different actors can thus result in multiple outcomes, such that a technology's affordance refers to what its material properties may actually achieve for a given individual (Markus \& Silver, 2008).

Social practices shape the affordances of technology (Orlikowski \& Scott, 2008); at the same time, the affordances of a technology can be defined based on the social practice(s) it enables. Sociomaterial practices are considered spaces within which people engage with the materiality of technological artifacts to produce various outcomes (Orlikowski \& Scott, 2008). This moves affordances beyond the exclusive property of either a social actor or a given technology, toward a relationship between people and the material artifacts with which they come in contact through a set of social practices (Hutchby, 2001).

In order to capture the affordances of different digital technologies, it is essential to focus on the social practices that they enable. Features of technologies are "materialized" only if their use by MKWs is consequential in how these workers carry out their work and personal practices. There is a diverse set of practices that undergird the work and personal lives of MKWs; however, common to all of them is the mobilization work or mobilizing information practices that enable MKWs to shape their understanding about solutions to problems related to working across multiple places (Perry, 2007).

By employing the affordance perspective and focusing on the common information practices of MKWs, this paper describes how the use of various ICT genres enables MKWs to generate different affordances and outcomes, mobilizing their impact beyond the traditional, centralized office space. 


\section{Methodology}

Our sample consisted of 33 mobile knowledge workers mostly from North Carolina's Research Triangle. Data was gathered through in-depth, semi-structured interviews with all participants and the additional collection of research diaries from 12 of the same participants. Participants were chosen for inclusion based on three criteria: their engagement in knowledge work; mobility in their work; and centrality of nomadic practices to their work. Knowledge work involves the creation or transmission of knowledge; is intellectual and creative; requires both theoretical and technical knowledge; and requires a formal education (Schultze, 2000).

Participants were identified through purposive sampling of possible contacts developed from our engagement with community-based freelance and entrepreneurial groups in North Carolina, online searches of local freelancers, websites such as nomadlist.com, and the personal recommendations of interviewees. Snowball sampling was used to increase the sample size, and finally theoretical sampling was used to increase the number of certain types of MKWs. Specifically, more individuals with high "nomadic-like" mobility were sought out. Of the 33 participants 13 are female and 20 are male. They range in age from mid-twenties to mid-sixties, and all have attained a certain level of technical competence. Four of our participants work at large organizations, three at medium organizations, eight at small organizations, and eighteen work as freelancers. Selecting participants from organizations of various size enabled us to draw attention to an important aspect of mobility: Organizational resources and constraints that are deemed central in the work practices of MKWs and tend to vary across solo, small and large organizations. Participants hold positions such as IT Consultant, Web Developer, Realtor, Attorney, Writer, and Digital Marketer.

In interviews, participants discussed their work tasks and work spaces; the tools they used to do their jobs; and their strategies for being effective MKWs. Interviews lasted 50 to 90 minutes and were audio recorded and transcribed.

Diary data was collected from 12 of the original 33 participants who were especially mobile, and therefore of particular interest. Use of diaries allowed for in situ data collection about mobile knowledge work, and provided further insight into participants' practices in naturalistic settings over a longer period of time (Grinter \& Eldridge, 2001). Interview data may be susceptible to recall bias; therefore, diaries provided useful additional information, data being collected as close to the unfolding of events and practices as possible.

Diaries do have their own limitations. It is possible that participants might share only what they feel like sharing. In order to somewhat reduce the likelihood of this occurring, we used a questionnaire to guide the participants" responses. Participants might also have become self-conscious and changed their behaviors because they were recording them. Finally, both diaries and interviews rely on self-awareness. Participants are unable to discuss behaviors they have not noticed themselves using. 
The work day of a MKW involves frequently shifting social and spatial environments (Ciolfi \& de Carvalho, 2014), making direct researcher observation difficult. However, participants were able to complete the diary entries from any location and on any device, completing a brief questionnaire about work activities and ICTs and taking pictures as possible. We created questions based findings from the initial interviews with the participants. The questionnaire was a mix of multiple-choice and open-ended questions enquiring about what work had been occupying our participants' time and what technologies they had been using. As part of the questionnaire, participants were asked to upload pictures of their environment and power source.

The questionnaire was emailed to participants twice a day for 7-10 days. Participants were asked to complete both diary entries per day during the duration of the study and to submit them through online survey software from a computer or mobile device. We primarily used Qualtrics software to collect diary entries from our participants who used either their smart phones or laptops to submit responses.

Participants were compensated $\$ 3$ per entry, given by gift card after the completion of the diary collection (e.g., 2 entries per day for 7 days $=\$ 42$ gift card).

Data collection and analysis proceeded concurrently. NVivo research software was used to facilitate analysis. The interview transcripts were coded for information practices that enabled workers to mobilize their work as well as the digital technologies that scaffolded these practices. The coded quotations were brought together across interviews to form a bigger picture of the information practices of Mobile Knowledge Workers.

The research was funded by the University of North Carolina School of Information and Library Science Kilgour Research Grant.

\section{Findings}

Our analysis has given rise to five mobilizing information practices that enable MKWs to perform work across different locations and while traveling between locations. These practices generate a critical "understanding" (McKenzie, 2009) or "literacy" (Lloyd, 2003) relative to how best to carry out work responsibilities outside of a centralized office work environment. The information practices identified here are connected to tangible information - to information 'things' (Buckland, 1991)-but are also part of a broader repertoire of intangible information activities that enable day-to-day work productivity. Only one of the five information practices (ensuring information access) involved direct dealing with tangible and explicit forms of information artifacts/objects. The other four information practices represent generating and using tacit forms of information and situational awareness that is only gained through actual practice. Although these four practices certainly relate to tangible information, they are more about ground-up, extra-institutional or 
vernacular approaches to knowing one's work on one's own terms (Lloyd, 2014). All of these information practices are intertwined with a diverse use of ICTs. In what follows, we describe the enabling roles played by these digital technologies.

\subsection{Ensuring information access}

Throughout their workday, MKWs strive to maintain access to all of the information they need to accomplish their work. Wherever they are working and with whatever devices they have at hand, they must be able to retrieve relevant documents, emails, social network tools, and websites.

It is evident that even uncomplicated spatial mobility requires that a worker entwine his or her information practices with digital technologies. Technologies act very much as the threads that bind and link the work our participants do to their intended recipients, thereby enabling a mobile knowledge professional to be mobile. Because technology is so central to the accessibility of MKWs' information, we observed that participants moved towards more and more technology usage.

Information practices that previously have been handled in physical, paper-based formats are increasingly and even retroactively being transferred to the digital realm. Many of our participants scanned what they needed for work that existed only in paper format to ease the burden of having to carry around copious amounts of paper or to eliminate the risk of losing important documents (e.g., P2, P5, P7), and to facilitate easy search-and-retrieval (e.g., P4). Still others often made use of voice recorder apps on their mobile phones (e.g., P3, P7). This increasing turn to digitization is further propelled as software programs and applications continually update and enhance their available features. In this vein, one participant (P5) reflected on the rarity of his needing to print and scan documents anymore: "About 2 years ago, there was an update to the Mac OS that their preview made it really easy to sign PDF's [...] digitally. And so since I was able to do that, it's really easy; I don't have to print out things the way I used to [...] But now... since it's really easy to sign it digitally, I just do that. And never print it out."

Digitized information is convenient because MKWs can access it from the devices that travel with them, such as laptops and smartphones. However, information stored on the cloud is even more useful, as it can be accessed from any device. "It doesn't matter what machine I use. The machine is almost irrelevant... it's freed me up a lot. [...] As long as I have an Internet connection, and some kind of computing device, I could work" (P6). Cloud storage is, importantly, device-agnostic. The accessibility of information stored on the cloud is especially important to MKWs who travel far from their home offices. P7 got a referral for a new client in San Diego while visiting San Diego on business. She said that she usually would prepare her client documents before a trip to meet in person. "So, luckily for me, if I didn't have everything on Skydrive, I would not have 
been able to duplicate all my documents I need because I wouldn't have had them accessible, I would only have what I normally bring with me" (P7). She was able to access the needed documents from the cloud so she could be fully prepared to meet her new client while in town.

The cloud may be used to backup information that is also stored elsewhere with the idea that, should the information be needed, it will be available. When P29's phone crashed during a call on a business trip and all his contacts disappeared, he was able to "go to the hotel and log into my iCloud to look for the contact information and call the people back" (P29). P29 doesn't regularly access his contacts through iCloud, but it was essential for him to have access to the information there in this instance.

The tradeoff for accessibility can be security. Because of this, several participants preferred cloud technologies that focused on security, enabling them to take advantage of easy accessibility without sacrificing confidentiality. P33 prefers SpiderOak for cloud storage because "[t]hey have a zero knowledge privacy policy." According to their website this means they "know nothing about the encrypted data you store on our servers" 1 . In general, MKWs, especially those who handle sensitive information, do not want to trade mobile access for privacy.

Smart phones free workers from carrying a lot of information resources and documents, serving as powerful conduits for interactions with colleagues (e.g., via email or instant messaging) and access providers to information needed for work on the move. In an early study of the role of mobile phones in mobile work contexts, Perry et al. (2001) presented the mobile phone as an indirect and imperfect means for accessing information. Phone calls were not considered sufficient to complete transactions, given that necessary information was often lacking. However, we found that smartphones now offer so many embedded features, such as email and Internet access, that MKWs can use them as "mobile offices" if need be. Smartphone apps can also be particularly useful during travel. P9 uses apps to check on his flight status and request a car from Uber. Furthermore, smart phones with voice control enable MKWs to access information hands free while in transit; for example, P8 has Siri read emails when driving.

Some communication and organization technologies improve access by actively drawing users' attention to things that are important, or pushing relevant information to them. P10 has the Clio calendar "pushed to the Google Calendar that we have, then pushed to mobile devices, or computers." P10 also uses an email organizer that "will move less important emails out of my inbox automatically. So what ends up in my inbox is generally important stuff." P24 likes the collaboration tool Slack because it brings notifications from other applications together in one place. Similarly, P33 uses an application called 17Hats that, as all-in-one service,

\footnotetext{
${ }^{1}$ https://spideroak.com/features/zero-knowledge
} 
allows her to see and integrate all the notifications and other important information in the same dashboard (Figure 1). MKWs have so much digital information that important information is only truly accessible if it stands out.

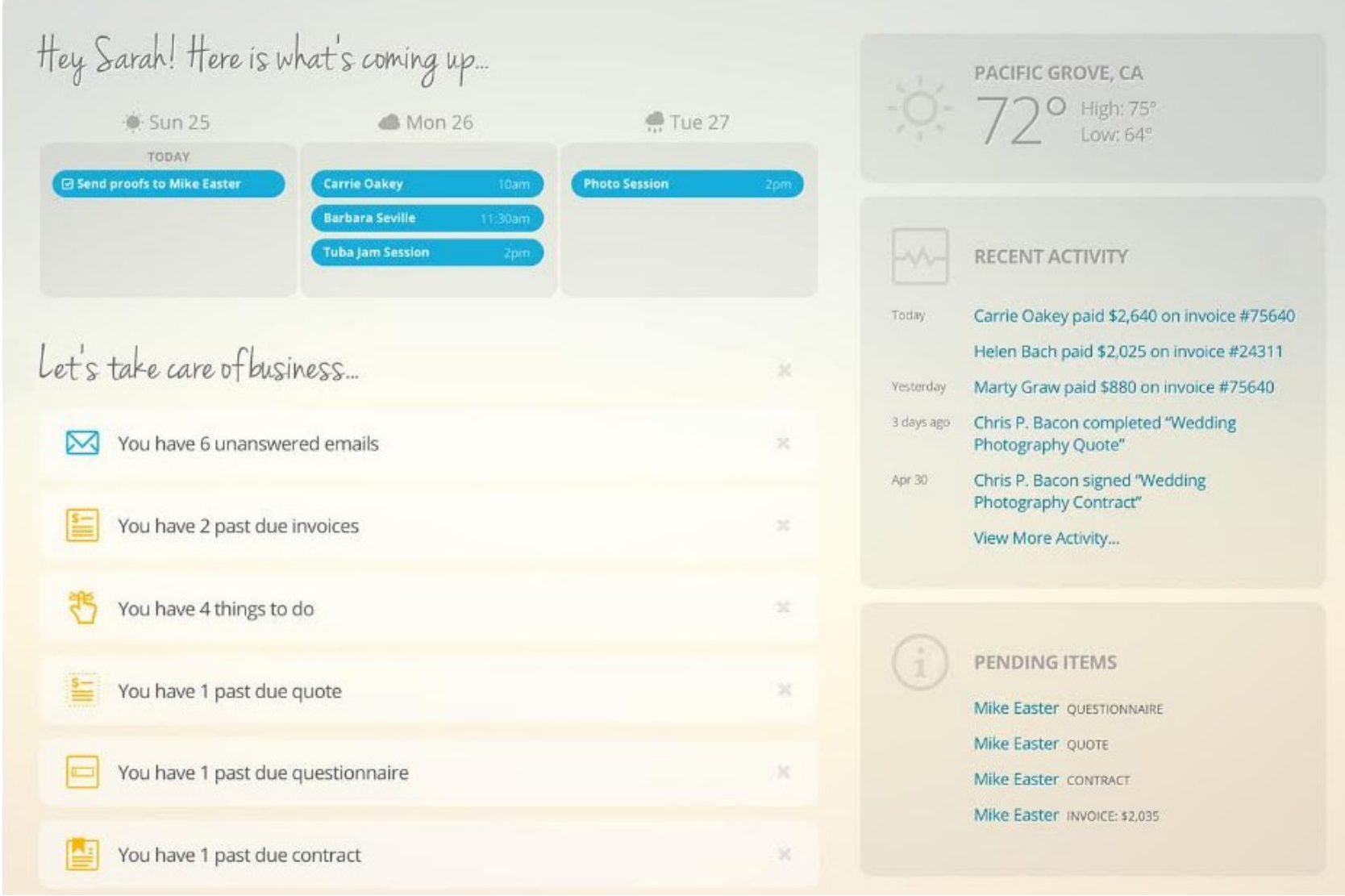

Figure 1. 17Hats dashboard aggregating multiple sources of information (taken from https://www.17hats.com/features.html).

\subsection{Keeping social cohesion}

MKWs exercise technological acuity as they take measures to remain viable throughout the workday. They must make an effort to ensure that all their technology is working properly and that they will have other necessities such as power and an Internet connection. Many of our participants devoted time to increasing their technological acuity as it was so important to their work-life.

There are many online communities and online interactions that enable workers to raise their knowledge about digital infrastructures and give advice on handling common technological issues. For example, websites 
such as Nomad List ${ }^{2}$ or Where My Nomads $\mathrm{At}^{3}$ provide opportunities to interact with nomadic workers with similar work styles and technological challenges. Hashtags like \#MobileWorkers and \#Coworking similarly facilitate conversations about the (technological) challenges and opportunities of mobile work. Those travelling frequently may consult websites such as seatguru.com to find out about the arrangement of airplane laptop powerports. All of these resources help MKWs learn how to become even more effective professionals in their mobile environments.

In addition to leveraging explicit online information sources, technological acuity can arise from situated engagement around and with technological infrastructures. Through this, an MKW learns how to benefit from a system, for example by hacking the system when they can. On flights, P13, a web developer, found a way to utilize the Internet connection without having to pay for it: "I love when planes have in flight Wi-Fi because I don't actually pay for it. What's really funny is that when I'm developing [web applications], it's happening locally on my computer. Well we still have to make calls, like API calls out to other services. All those in flight Wi-Fi services redirect continually to this page, which is where you get to pay; that's all it does over and over again. You still have an Internet connection so the calls from my local website that I'm hosting still get on perfectly fine so I can run our website on my laptop $100 \%$ just like I would if I was at home or at a co-work space. So I can develop with absolutely no hindrance on the flight without paying any money." P13 has gained higher technological acuity through his repeated engagement with this particular information situation (needing to develop web applications while on a plane).

As another example, P22 uses an app (WiFi Analyzer) that identifies the fastest WiFi in a neighborhood: "I've got on my phone an app that lists the WiFi networks in the area and it shows a graph showing the strength of the signal, and so I can just walk around the neighborhood and keep track of which network IDs I see. Whether they're open, whether they have a password on them, how strong the network is. And from walking around the neighborhood and finding that, we were able to locate there's a coffee shop at the bottom of our building." The app acted as a beacon, locating the origin of the signal and allowing P22 to learn where to find the best public Internet connection, and therefore the best place from which to work.

\subsection{Maintaining technological acuity}

MKWs spend a great deal of time in a different physical location from the other people with whom (or for whom) they work. They must find ways to be "seen" by their clients and colleagues and maintain professional relationships.

\footnotetext{
${ }^{2}$ https://nomadlist.com

${ }^{3}$ http://www.where-my-nomads.at/
} 
Many MKWs use social media to remain visible and accessible. P23 literally shows others where she is working, posting pictures of her mobile office to social media, because, "people like that." Clients communicate with P8 through social media: "They've used Facebook to message us. They've even used Twitter." P33 gets a lot of my clients through "a group on Facebook for entrepreneurs--they'll get to know me and they know I'm an editor and then think of you when they need an editor." P20 also says she and her husband have gotten jobs through social media. "We don't know the person, but the person may say they feel like they knew us because of our social media presence and blogs" (P20). MKWs expand and maintain their professional network through social media.

This may be the reason that many MKWs regularly devote time to updating their social media profiles and advertising on social media. In diaries of their work activities some of our MKWs shared that every few days they engaged in such tasks as:

"[S]haring links to my various projects through social media groups" (P22).

"[P]romoting friend's new book via social media" (P26).

"Participating in Facebook groups" (P30).

"Creating page on my website for a new offering. Sharing it on Facebook" (P33).

MKWs use other communication technologies strategically to project their professional image. P11 deliberately preserves the automatic iPhone signature line "Sent from my iPhone" to make a point about his availability: "It kind of shows that, hey, you called me away from my computer and I still answered. It's more remarketing." P11 wants his clients to know that he is accessible anywhere. Others must send a very different message. Some of P28's clients get "bent out of shape" when they know she is out of the country. She uses a United States Skype number so "they don't have to know where I am" (P28). Although P28 is available to her clients anywhere, they feel more comfortable if they believe she is nearby and so she makes it seem that she is.

Appearing professional in a video conference can be very important depending on an MKW's line of work. P22 creates an intentional backdrop for his video conferences, including covering up a closet on the wall behind his desk. He wrote in a diary entry: "This red backdrop creates a more professional look when I'm on video and hides the mess inside the closet" (P22). In addition to this, P22 uses "a quality mic running to a mixer" to ensure good sound during video conferences. P22 puts effort into crafting the audio and visual impression he will make during a video conference (Figure 2) 

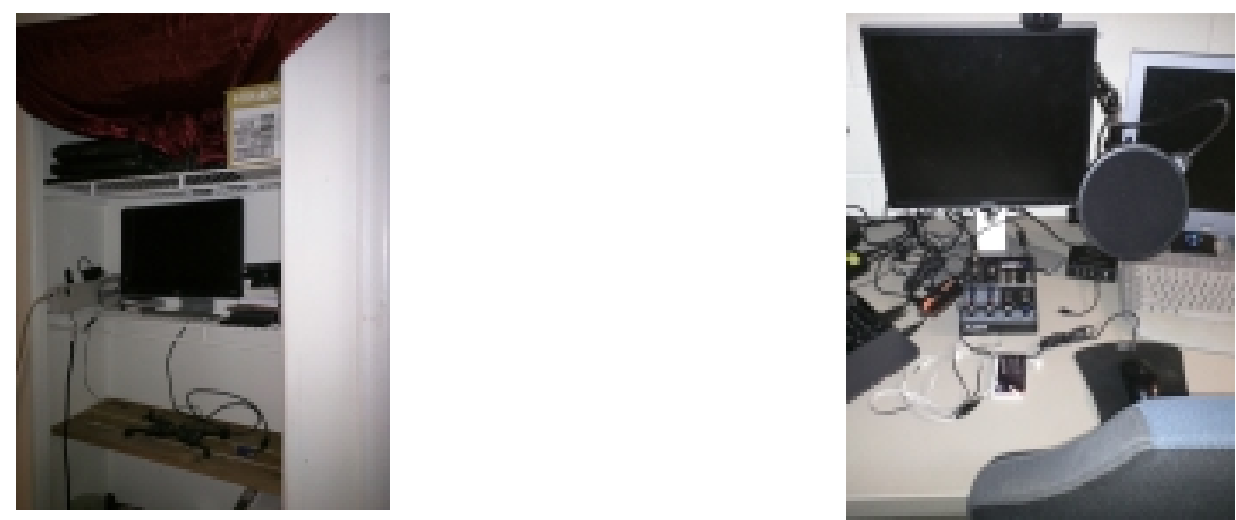

Figure 2. P22's closet, curtain, and microphone and mixer (photos sent through the diary postings).

\subsection{Upholding work rhythm}

Although MKWs may not work a typical 9 to 5 workday, they have times when they want to get work done, and must ensure that they can do it. There are many things that can impact a MKW's work rhythm, such as travel by car or airplane or the need to collaborate with a colleague in another time zone. MKWs find ways to work through or around these challenges.

MKWs sometimes need to travel light. Small mobile devices allow them to get work done even on these occasions. P31 will choose her tablet over her laptop because "it fits perfectly" in her purse. Mobile applications make these devices powerful tools that allow MKWs to do a number of work tasks while on the go. P29 asserts that he "could write a whole contract" on his phone because "everything comes out perfectly" in the app. For many of our participants their mobile office could be just their smartphone if that was all they had on hand.

Travel, especially longer distance travel, has the potential to interrupt a MKW's work rhythm. Our Participants had different ways of approaching travel. Some of them take advantage of the lack of WiFi during a plane flight by using that time to do work that does not require the Internet. P27 said, "you're not tempted to go surf the Internet or go look something up and get distracted. You focus." In this case, non-connectivity is recognized as an opportunity for distraction free work. Contrastingly, other MKWs seek out travel options that allow them constant connectivity. P25 chooses to travel by train because there are "a couple of Amtrak routes here on the West Coast that have really reliable WiFi." P25's workday, which requires Internet, is hardly interrupted by travel at all.

Car travel was frequently mentioned by our participants. P7 spends a lot of time traveling in her car to see clients. While she is on the go, she uses her phone with a headset to set appointment times, and make voice notes and reminders, utilizing Siri's hands-free, speech recognition capabilities. For longer notes, she may use Google Voice because it will send a transcript to her email. P5 "did a bunch a work sitting in the passenger 
seat" on a trip to Miami while his wife drove. He said, "I work directly on my laptop, and I have a web server and everything running on my laptop, so I can do what I need there. I can... tether my phone, and, access the Internet that way." Several participants (e.g., P3, P7, P8), asserted that conference calls and voice memos were essential to their mobile information practices: "If I didn't have voice recorder as an app, life would be very difficult. It's for... every time I get an idea, things I have to remember to do. I live on a to-do list, my to do list. [...] Because I'm so mobile, voice is critical to me" (P3). Several also mentioned using iPads, iPods, iPhones, and other tablets to access professional literature, instructional YouTube videos, or business-related podcasts while mobile. Noted one, "I just turn my car into a rolling university" (P9). Many mobile technologies enable MKWs to continue working, even while on the road.

MKWs may work with colleagues or clients who are located all over the nation, or world. There are times when their work rhythms must be synchronized, for example, during phone or video conferences, which means accounting for time differences. In her diary, P33 said that one of her challenges was "Wrangling time zones," and she overcame this challenge by using worldtimebuddy.com. This site is specially designed to aid in scheduling meetings across time zones.

\subsection{Enacting personal-professional balance}

Because of the flexibility of their work time and space, MKWs can find that work creeps into their personal lives. They attempt to create balance by more deliberately deciding how they will integrate their contexts and/or setting up boundaries to keep them separate.

Some of our participants use an alarm on their phone or computer to schedule times to pause in their work. One of these alarms went off during P2's interview. "It's my reminder to breathe every once in a while. You know, like mindfulness" (P2). P27 uses the alarm on her phone "to remind me to take a break." These MKWs purposely interrupt their work to take time for personal care.

Managing the balance between personal and professional time includes making time to be with loved ones. Shared calendars allow MKWs to coordinate their schedules with others: "So finally we were like 'alright, why don't we just get each other's calendar on there,' and then we know what each person's doing, and then we can figure out how to plan time to hang out from there" (P8). The shared calendar allows P8 and his girlfriend to see instantly when they are both free.

Travel is a big part of some MKWs' schedules. They may choose to try and get work done during that time, as seen in the examples of using voice controls to read and answer emails or listening to professional podcasts. But some MKWs take travel time as personal time by listening to audio books for pleasure. For P3, audio books, "let me escape" and P21 believes that listening to books while driving "reduces road rage." 
Mobile technologies can allow MKWs to choose an appealing environment in which to set up. In one of his diary entries, P22 said that, "Having to get some work done on such a beautiful day was a challenge. I decided to move my work space out to the patio to enjoy the mountain view and beautiful weather." P26 also needed a "change of scenery" and shared in his diary, "Going out to lunch and working from [a] cafe helped!" MKWs can accommodate personal comfort by putting themselves in an aesthetically pleasing physical location, and continue working through their mobile technology.

\section{Discussion}

Technology not only makes MKWs more mobile physically, but also allows them the mobility to cross the many different kinds of boundaries they encounter. Cousins and Robey (2005) note that complicating mobility beyond simply spatial mobility is important "in explaining the patterns of nomadic work" (p. 178). MKWs are able to achieve mobility along multiple dimensions through the use of a combination of digital technologies. For example, digitally mediated information practices of upholding work rhythms and ensuring information access help workers to mobilize their work along spatial and temporal dimensions. Affordances of various ICTs for mobile knowledge work can be understood based on how their use enables the mobilization of work. Assemblages of technologies generate affordances for spanning work boundaries and mobilizing work by enabling different information practices.

It is important to note that differences in organizational and financial resources can impact the way each participant viewed and enacted these affordances. Access to more superior technological resources such as enterprise communication tools (e.g., a premium subscription of GotoMeeting) assures an easier mobilization of work practices across time and space. Not all of the MKWs included in this study (particularly those operating as solo workers or freelancers) were able to take advantage of these enterprise resources. This noted, lack of access to these resources could have led to experimentation with a broad range of free or inexpensive suites of tools, application and networks; such efforts based on trial and error in turn may result in higher technological literacies and awareness about advantages and disadvantages of ubiquitous technologies in across different places, times and organizational boundaries.

\subsection{Spatial mobilization}

Geographic or spatial boundaries, such as a lack of reliable access to information sources across multiple locations, have been considered the most visible impediment of work in contemporary organizations (Watson-Manheim, Chudoba, \& Crowston, 2012). Mobile-friendly technologies now enable spatial, and consequently, temporal, freedoms. By granting users the ability to access information and tools while on the go, their flexibility to meet with clients, engage in short- and long-distance travel, and work from anywhere 
immediately convenient is heightened. In addition, rather than hopping on and off of WiFi signals from surrounding buildings, most MKWs who move about during the workday can stay constantly connected through their phones. For example, P15 uses "4G across whatever building I go to" and never loses Internet connection. Consequently, many of our participants defined their office as 'wherever' they have access to their cell phones and their laptops.

\subsection{Temporal mobilization}

The use of ICTs creates temporal flexibility, enabling workers to more flexibly organize their work and personal lives. Several participants appreciate the fact that they are able to access work resources on their smartphones and stay in touch with colleagues while accomplishing personal errands. Many have created strategies for multitasking and attending to both personal and work matters at the same time. For instance, P4 uses the mute button to take care of personal business while on work calls, divulging that "I'll do everything from feedin' the cats and doin' chores around the house." As another example, features like voice recognition also enable MKWs to take advantage of deadtime when moving through airports, in cars, or between meetings. The majority mentioned holding conference calls and using voice-memo features on their mobile phones while driving from location to location.

\subsection{Social mobilization}

Mobile work often comes with a distance from a central organizational locus, which translates into the absence of informal mechanisms for 'keeping in touch' with others. Through social mobilization MKWs maintain and extend the social infrastructure needed for conducting knowledge work (Jarrahi \& Sawyer, 2015). Several digital technologies, particularly social technologies, can provide relevant affordances that can facilitate interaction with others and maintenance of the social infrastructure. For example, cloud storage allows MKWs to collaborate and communicate on projects with colleagues and clients. As mentioned above, MKWs also attract $(\mathrm{P} 33, \mathrm{P} 20)$ and communicate with $(\mathrm{P} 23, \mathrm{P} 8)$ clients using social media. Many of them regularly spend a portion of their workday maintaining their social media presence and advertising on social media (P22, P26, P30, P33).

In diary responses we learned how our participants coordinate their social presence on a daily basis. P25, for example, began multiple diary entries with "catching up on Slack" (a messaging application used for collaborative work). Another had frequent coaching calls with clients on Skype (P33), and there were numerous mentions of emails (P7, P20, P22, P25, P26, P30, P33, P34) and phone calls (P7, P22, P26, P30). MKWs take advantage of new technologies that enable collaboration, but still rely heavily on relatively older communication technologies as well, to keep them connected to other people. 


\subsection{Contextual mobilization}

Cousins and Robey (2005) describe contextual mobilization as movement, enabled by technology, between the multiple social roles a MKW plays (p. 152). As described above, in the discussion of enacting personalprofessional balance, technology does encourage the blending of personal and professional. Work and personal life intermingle when, for example, the same computer an MKW uses to do his or her job displays a reminder to take a break. Conflation of personal and professional lives fueled by the use of technology is not unique to MKWs, but it also increasingly plagues more traditional forms of work arrangements. However, this effect is much more pronounced in mobile work as by the very nature of mobile work style, traditional spatial and temporal boundaries that demarcate between workplace and home in conventional forms of work are less relevant in MKWs. As a result, for MKWs, technology tends to plays a more visible role in context collapse. Because blending of personal and professional lives comes so naturally to MKWs, what many now need from their technology is a way to deliberately keep the two spheres separate. Contextual mobilization for our participants means using technologies that allow them to move between personal and professional contexts on their own terms, as context collapse can be a barrier to productivity. Digital technologies are often coopted to mitigate the negative effects of mobile work. As a common strategy, many MKWs keep their personal and professional contexts separate, doing certain activities on certain devices (e.g., P7, P12, P14). P7 only gets work related email on her laptop. "I do not have any other email come into it" (P7). P12 only checks work email on the work laptop. "I think it helps me work more. It helps me focus more. It just makes that barrier. If I want to check my [personal] email, I can do it on my iPhone" (P12). P14 keeps personal documents in Google Drive, and collaborates on work documents using Dropbox. These MKWs are trying to keep their personal context out of their professional context. We consider the motivation for separating the two contexts to be a useful direction for future research; in particular, why MKWs still see the need to reinforce the boundaries despite the fact that spatial and temporal flexibility are often cited as alluring aspects of their work.

\section{Conclusion}

This paper explored how MKWs' information practices are mediated through highly individualized arrays or assemblages of ICT devices and systems. The use of these technologies has changed when, where, and how MKWs deal with professional matters. They have been found to pass along and forward more information to colleagues than they would if co-located, to make use of 'dead time' to manage information, and to deal with received information outside of normal work hours. In an ever-increasing spiral, such devices may ostensibly ease the anxieties of being away from the office, but at the same time "further reinforce a need to be continually contactable" (Allen \& Shoard, 2005). 
The affordance perspective provides a helpful foundation for capturing and explicating the roles played by assemblages of digital technologies in facilitating the information practices of MKWs. A focus on information practices offers a useful social context for understanding how a variety of ICTs 'scaffold' work practices of MKWs (Orlikowski, 2006), delivering a sophisticated account of material mediation (technology enablement) without sliding into simplistic technologically deterministic explanations of technological effects (Faraj \& Azad, 2012). Affordances of ICTs are enacted in more complicated ways in the work practices of MKWs. Work environment greatly shifts when work is mobilized, as MKWs have looser ties to an organization (or perhaps are singularly affiliated with no organization at all), and their mobility becomes more complicated than simply being geographic. Spatial mobility as the most visible defining factor of MKWs comes with other forms of mobility, all enabled by the use of digital technologies. These different but interrelated mobilities demonstrate the affordances of digital technologies in relation to the information practices they enable. We underscored spatial, temporal, contextual, and social mobilization as distinct affordances of assemblages of digital technologies when used by MKWs to support key information practices performed to accomplish work, away and independent from traditional organizational spheres of control.

From a sociotechnical perspective, the relationship between information practices and these emergent digital infrastructures is mutually constitutive; while a wide variety of ICTs support the information practices of MKWs, the configuration and bottom-up nature of these individualized digital infrastructures are shaped by the unique information practices of MKWs. In adapting to their dynamic work situations and in order to conduct information practices on the move, MKWs tend to configure and reconfigure their own infrastructures, ones enacted in practice, and ones which involve a high degree of improvisation, bricolaging, and working-around. Rather than being 'designed' or 'built' through top-down organizational mechanisms, 'emergent digital infrastructures' are therefore incomplete, open, and reflect bottom-up information practices of MKWs. All participants of this research share the experience of enacting and maintaining their needed mobile work resources apart from any centralized organizational locus, drawing upon a wide variety of digital technologies in the process. These ICT assemblages comprise desktops, laptops, tablets, mobile phones, printers (or, at least, access to a pay-per-use printer), headphones, and a variety of cables and charging devices, with as many as four backup chargers. Dropbox, One Drive, Google Drive, Facebook, Twitter, LinkedIn, professional Listservs, newsletters, Hangouts and Skype, note-keeping and to-do-listing applications were also central parts of assemblages. Ubiquitous and consumer-directed technologies have noticeable roles here, reflecting the autonomy and choice surrounding technology, based on subjective notions such as ease of use and aesthetics. P29 notes, "I think the adding of the apps have made me a lot more mobile. I remember when I had the Blackberry Treo. Really, you couldn't write a contract from that phone. You couldn't do much. All the apps fit so perfectly in your phone [now]. Everything comes out perfectly on your app." 
Understanding MKW context and the unique role of ICTs can provide rich accounts to organizational managers who are increasingly called upon to motivate and manage mobile workforces. Most MKWs often operate in the an ambiguous and 'liminal space,' in which they occupy ongoing temporary and "in-between" positions (Borg \& Söderlund, 2014). These workers are not considered complete insiders nor complete outsiders. In such a context, staying abreast of the organization is vital for MKWs, as they may not be cohesively connected to the social infrastructure within and between organizations. Social technologies can therefore be used as a vehicle to connect and integrate MKWs with the organizational social networks that serve as the primary conduit of informal knowledge. Furthermore, many MKWs in our sample increasingly build upon their own personal technologies, such as personal cloud services or personal mobile devices, to conduct their work on the move. One of our participants often carries two different laptops because the organizational regulations restrict him from using specific software such as Google applications on his work laptop. He needs the work laptop to access the organizational resources, so he carries out his work on two parallel laptops. He uses email to transfer the needed files across the two laptops, because both cloud storage services and external drives are restricted on his work computer. This situation exemplifies how overly restrictive organizational policies and enterprise digital infrastructures may alienate MKWs by constraining their use of personal and ubiquitous technologies.

While this papers seeks to enhance the research on the roles played by ICTs in work practices of MKWs, we acknowledge its limitations. The first limitation lies in the theoretical foundation of this work. As the term "affordance" connotes, the affordance framework is weighted towards the enabling roles plaid by ICTs, and does not necessarily embrace the way through which these technologies may constrain the work practices of mobile workers. The digital infrastructure outside the conventional office and across multiple workplaces is not always "seamless," and poses technological constraints that impede the work of mobile workers (Erickson \& Jarrahi, 2016; Santosa \& Wigdor, 2013). Therefore, future work is needed to examine how various ICTs play double roles, and specifically how MKWs dedicate some of their efforts to dealing with the uncertainty of digital infrastructures on the move, and to mobilize technology itself. The second limitation has to do with the methodology employed in this research. We recognize that our empirical study like most research on the use of technologies in mobile work has been conducted in Europe and United States, and we specifically focused on the North Carolina Research Traingle Park (RTP), which reflect a unique state and city level resources and local contingeinces. For example, studying MKWs in RTP presents a different set of challenges for workers characterized by a more distributed suburban environment (compared to, lets say, New York City); in addition, even though some of our participants travelled internationally quite frequently, and reflected upon their experience working in other countries, our findings are greatly skewed towards the work 
contexts and digital infrastructures in the United States. Future empirical research can explore other local and national contexts (e.g., the developing world) and compare the findings. 
Allen, D., Karanasios, S., \& Slavova, M. (2011). Working with activity theory: Context, technology, and information behavior. Journal of the American Society for Information Science and Technology, 62(4), 776-788.

Allen, D., Wilson, T., Norman, A., \& Knight, C. (2008). Information on the move: the use of mobile information systems by UK police forces. Information Research, 13(4).

Allen, K., \& Shoard, M. (2005). Spreading the load: mobile information and communications technologies and their effect on information overload. Information Research, 10(2).

Bardram, J. E., \& Bossen, C. (2005). Mobility work: The spatial dimension of collaboration at a hospital. Computer Supported Cooperative Work (CSCW), 14(2), 131-160.

Borg, E., \& Söderlund, J. (2014). Liminality competence: An interpretative study of mobile project workers' conception of liminality at work. Management Learning, 1350507613516247.

Buckland, M. K. (1991). Information as thing. Journal of the Association for Information Science and Technology, 42(5), 351-360.

Ciolfi, L., \& de Carvalho, A. F. P. (2014). Work Practices, Nomadicity and the Mediational Role of Technology. Computer Supported Cooperative Work (CSCW), 23(2), 119-136.

Costas, J. (2013). Problematizing mobility: A metaphor of stickiness, non-places and the kinetic elite. Organization Studies, 34(10), 1467-1485.

Courtright, C. (2007). Context in information behavior research. Annual review of information science and technology, 41(1), 273-306.

Cousins, K. C., \& Robey, D. (2005). Human agency in a wireless world: Patterns of technology use in nomadic computing environments. Information and Organization, 15(2), 151-180.

Czarniawska, B. (2014). Nomadic work as life-story plot. Computer Supported Cooperative Work (CSCW), 23(2), 205-221.

Davis, G. (2002). Anytime/anyplace computing and the future of knowledge work. Communications of the ACM, 45(12), 67-73.

Erickson, I., \& Jarrahi, M. H. (2016). Infrastructuring and the Challenge of Dynamic Seams in Mobile Knowledge Work. Paper presented at the Proceedings of the ACM Conference on Computer Supported Cooperative Work \& Social Computing, San Fransisco, CA.

Erickson, I., Jarrahi, M. H., Thomson, L., \& Sawyer, S. (2014). More than nomads: Mobility, knowledge work, and infrastructure. Paper presented at the the European Group for Organizational Studies Colloquium, Rotterdam, The Netherlands.

Faraj, S., \& Azad, B. (2012). The materiality of technology: An affordance perspective. In P. M. Leonardi, B. Nardi, \& J. Kallinikos (Eds.), Materiality and organizing: Social interaction in a technological world (pp. 237-258). Oxford: Oxford University Press.

Gibson, J. (1977). The theory of affordances. In R. Shaw \& J. Bransfor (Eds.), Perceiving, acting, and knowing: Toward an ecological psychology (pp. 67-82). Hillsdale, NJ: Lawrence Erlbaum Associates.

Grinter, R. E., \& Eldridge, M. A. (2001). y do tngrs luv 2 txt msg? Paper presented at the ECSCW 2001, Bonn, Germany.

Huotari, M.-L., \& Chatman, E. (2002). Using everyday life information seeking to explain organizational behavior. Library \& Information Science Research, 23(4), 351-366.

Huotari, M.-L., \& Wilson, T. D. (2001). Determining organizational information needs: the critical success factors approach. Information Research, 6(3), 6-3.

Hutchby, I. (2001). Technologies, texts and affordances. Sociology, 35(2), 441-456.

IDC. (2015). IDC Forecasts U.S. Mobile Worker Population to Surpass 105 Million by 2020 Retrieved 15 June, 2016 from https://www.idc.com/getdoc.jsp?containerld=prUS25705415 
Jarrahi, M. H., \& Sawyer, S. (2015). Theorizing on the take-up of social technologies, organizational policies and norms, and consultants' knowledge-sharing practices. Journal of the Association for Information Science and Technology, 66(1), 162-179.

Jarrahi, M. H., \& Thomson, L. e. (forthcoming). The interplay between information practices and information context: The case of mobile knowledge workers. Journal of the Association for Information Science and Technology, 162-179.

Järvelin, K., \& Ingwersen, P. (2004). Information seeking research needs extension towards tasks and technology. Information Research, 10(1).

Julien, H., Pecoskie, J. J., \& Reed, K. (2011). Trends in information behavior research, 1999-2008: A content analysis. Library \& Information Science Research, 33(1), 19-24.

Karanasios, S., \& Allen, D. (2014). Mobile technology in mobile work: contradictions and congruencies in activity systems. European Journal of Information Systems, 23(5), 529-542.

Leckie, G. J., Pettigrew, K. E., \& Sylvain, C. (1996). Modeling the information seeking of professionals: a general model derived from research on engineers, health care professionals, and lawyers. The Library Quarterly, 161-193.

Lloyd, A. (2003). Information Literacy The Meta-Competency of the Knowledge Economy? An Exploratory Paper. Journal of Librarianship and information Science, 35(2), 87-92.

Lloyd, A. (2014). Following the red thread of information in information literacy research: Recovering local knowledge through interview to the double. Library \& Information Science Research, 36(2), 99-105.

Markus, M. L., \& Silver, M. S. (2008). A Foundation for the Study of IT Effects: A New Look at DeSanctis and Poole's Concepts of Structural Features and Spirit*. Journal of the Association for Information Systems, 9(10/11), 609.

McKenzie, P. J. (2009). Informing choice: The organization of institutional interaction in clinical midwifery care. Library \& Information Science Research, 31(3), 163-173.

Middleton, C. (2008). Do mobile technologies enable work-life balance? Dual perspectives on BlackBerry usage for supplemental work. In D. Hislop (Ed.), Mobility and technology in the workplace (pp. 209224). London: Routledge.

Mori, G., Paternò, F., \& Santoro, C. (2003). Tool support for designing nomadic applications. Paper presented at the Proceedings of the 8th international conference on Intelligent user interfaces.

Orlikowski, W., \& Scott, S. (2008). Sociomateriality: Challenging the Separation of Technology, Work and Organization. The Academy of Management Annals, 2(1), 433-474.

Orlikowski, W. J. (2006). Material knowing: the scaffolding of human knowledgeability. European Journal of Information Systems, 15(5), 460-480.

Orlikowski, W. J., \& lacono, C. S. (2001). Research commentary: Desperately seeking the "IT" in IT researchA call to theorizing the IT artifact. Information systems research, 12(2), 121-134.

Perry, M. (2007). Enabling nomadic work: developing the concept of 'Mobilisation Work'. Paper presented at the ECSCW 2007 Workshop: Beyond Mobility: Studying Nomadic Work Limerick, Ireland

Perry, M., \& Brodie, J. (2006). Virtually connected, practically mobile. In E. Andriesson \& M. Vartiainen (Eds.), Mobile Virtual Work: a New Paradigm (pp. 97-127). Berlin: Springer.

Rossitto, C., Bogdan, C., \& Severinson-Eklundh, K. (2014). Understanding Constellations of Technologies in Use in a Collaborative Nomadic Setting. Computer Supported Cooperative Work (CSCW), 23(2), 137161.

Santosa, S., \& Wigdor, D. (2013). A field study of multi-device workflows in distributed workspaces. Paper presented at the Proceedings of the ACM International Joint Conference on Pervasive and Ubiquitous Computing.

Sawyer, S., \& Huang, H. (2007). Conceptualizing information, technology, and people: Comparing information science and information systems literatures. Journal of the American Society for Information Science and Technology, 58(10), 1436-1447. 
Schultze, U. (2000). A confessional account of an ethnography about knowledge work. Management Information Systems Quarterly, 24(1), 3-42.

Sørensen, C. (2011). Enterprise Mobility: Tiny Technology with Global Impact on Work (Technology, Work, and Globalization). Palgrave Macmillan: London.

Su, N., \& Mark, G. (2008). Designing for nomadic work. Paper presented at the Proceeding of the 7th ACM conference on Designing interactive systems, Cape Town, South Africa.

Thomson, L., \& Jarrahi, M. (2014). Contextualising information practices and personal information management in mobile work. Paper presented at the Proceedings of ISIC, the Information Behaviour Conference, Leeds, UK.

Thomson, L., \& Jarrahi, M. H. (2015). Information Practices in the Broader 'Deportment' of Mobile Knowledge Work. Paper presented at the Proceedings of ASIST'15, Saint Louis, MI.

Veinot, T. (2007). "The Eyes of the Power Company": Workplace Information Practices of a Vault Inspector1. Library Quarterly, 77(2), 157-179.

Wang, Y., Van de Kar, E., \& Meijer, G. (2005). Designing mobile solutions for mobile workers: lessons learned from a case study. Paper presented at the Proceedings of the 7th international conference on Electronic commerce.

Watson-Manheim, M. B., Chudoba, K. M., \& Crowston, K. (2012). Perceived discontinuities and constructed continuities in virtual work. Information Systems Journal, 22(1), 29-52. 